\title{
Value Contribution of Rural E-commerce Development: Model Constructing and Empirical Testing
}

\author{
Xutang Chen ${ }^{1,2}$, Jingjing Wang ${ }^{2 *}$, Guoxin Yu ${ }^{1}$ \\ ${ }^{I}$ Department of Business, Lishui University, Zhejiang,China \\ ${ }^{2}$ School of Economics and Trade, Xinjiang Agricultural University, Xinjiang, China \\ *Corresponding Author.
}

\begin{abstract}
In the field of rural e-commerce, based on literature review, the paper constructs a four-dimensional value contribution model of rural e-commerce to economic, social, cultural, and ecological development. The value contribution scale for rural e-commerce development is designed to collect experts' opinions, then the measurement items are modified, and a questionnaire survey is conducted with farmers participating in rural e-commerce activities as the respondents. With AMOS software, a first-order structural equation model and a higher-order structural equation model are used to analyse the confirmatory factors of the rural e-commerce value contribution model, and to test the convergence and discriminative validity of the model and other important attributes. It can be concluded from the test results that the four value dimensions of the model show relatively high reliability and validity, which also suggest that the use of this model is highly rational in identifying the value contribution of the development of rural e-commerce, and has successfully developed the value contribution system of rural e-commerce as a formal theory. At the same time, according to the factor loading and the contribution rate of each principal component measured at the overall level, the weight of the principal components and indices of the overall dimension are achieved. Among the four value contribution dimensions, economic value shares the largest contribution brought by rural e-commerce development and ecological value shares the smallest. Therefore, these results and weights gained from this research will be used to determine the priority of the value contribution of rural e-commerce development, and will be taken into consideration in developing rural e-commerce.
\end{abstract}

Keywords: Rural e-commerce, value contribution, model

\section{Introduction}

With the widespread use of the Internet, especially the development of e-commerce in rural areas, channels for rural resources entering external markets have been broadened to a larger extent, allowing farmers to participate in more market activities, share information and encourage effective communication, which promote the sale of agricultural products. The use of internet and e-commerce plays new role in many aspects, namely rural industrial development, farmers' income increase, farmers' ability to get rid of poverty, farmers' better quality of life, entrepreneurship and employment. That is, the development of rural e-commerce contributes value to rural economic, social, cultural and ecological development: WaiShiang Cheah, Azman Bujang Masli and Edwin Mit [1] modeled the factors influencing the sustainability of e-commerce in rural communities, and the verification model showed positive results. Galloway L and Mochrie R [2] showed through a lot of evidence that information and communication technology (ICT) is the driving force of rural economic growth. The development of rural e-commerce has facilitated rural economic and social development, and promoted the integration of village culture [3]. E-commerce rebuilds the social and cultural environment in China's rural areas, facilitating cultural integration [4]. Liu Lili et al. [5] believed that e-commerce promotes agricultural green development and ecological environmental protection; Yingnan Zhang et al. [6] also proved that e-commerce has promoted the development of rural industries towards ecological integration. It can be concluded that the researches on the value contribution to 
the development of rural e-commerce have mostly focused on the analysis of a single aspect or a single module, and has not yet presented a complete value theory system structure, which is in a fragmented state.

As rural e-commerce has just emerged and been developing in the past few years, theoretical research on rural e-commerce and its value contribution are still in the exploratory stage. At present, the value contribution of rural e-commerce has yet neither generated a formal unified concept nor relevant empirical measurement tools, and empirical research on its composition theory requires new scales.

This research aims to build a rural e-commerce value contribution theoretical system based on the literature review of rural e-commerce value contribution. Through research data and AMOS software, a first-order structural equation model and a higher-order structural equation model will be used to conducts confirmatory factor analysis on the value contribution model, testing the model's convergence and discriminative validity and other important attributes, and then forms a complete rural e-commerce value contribution theory system.

The structure of this research is as follows: Part 2 introduces the relevant literature review, the economic, social, cultural, and ecological value of rural e-commerce development extracted from previous studies and verified by preliminary case studies; Part 3 builds a rural e-commerce value contribution model based on literature review; Part 4 expounds the research methods of this research; Part 5 features variable measurement and data collection; Part 6 identifies the structural validity and reliability of the model based on the survey data. According to the factor loading and the contribution rate of each principal component calculated according to the previous sections, Part 7 obtains the weight of the overall dimensional principal components and their indices; finally, the results are discussed in Part 8.

\section{Literature Review}

This paper selects the literature related to the development of rural e-commerce, classifies and counts the value contribution items in the literature, and extracts the indicators of the value contribution of the rural e-commerce development. The literature review is specifically carried out from four aspects: economy, society, culture and ecology.

In terms of economic value contribution, Khanal A and Mishra A [7] believed that small farms benefit from the use of the Internet. Compared with their peers, the annual agricultural cash income of agricultural households using the Internet has increased by approximately US\$9,500-12,400. Simple Jain and Anuprita Purohit [8] studied the utilization of e-Choupal by rural residents in four regions in Sri Lanka, namely Nagar, Kota, Balatpur and Chitolga. The results clearly show that e-Choupal has helped rural people obtain higher profits from crops in increasing agricultural production, adopting improved technologies, selling agricultural products and obtaining agricultural inputs in time. Alan Lukose [9] believed that farmers' adoption of e-commerce can help expand product coverage and increase turnover. Zhang Haibin and Zhang Guoqing [10] believed that an outstanding feature of e-commerce is that it can evaluate agricultural products online, which has an effect on the consumption behavior of other consumers and drives merchants to pay attention to product quality.

In terms of social value contribution, the main focus of research is on the role of rural e-commerce in improving the status of disadvantaged groups, employment and entrepreneurship, convenience of life, communication methods, and comprehensive quality improvement. Jo Rhodes [11] and Farhadi Fariba [12] maintained that rural e-commerce has the potentials to improve women's economic welfare, especially rural women's social status. Georgiadou K, Baros W, Kekkeris G [13] believed that e-commerce provides non-formal education and community empowerment for socially disadvantaged groups living in rural, remote and isolated areas.Amirhossein Alibaygi, Mehdi Karamidehkordi and Mehrdad Pouya [14] proved that the development of information and communication technology (ICT) in rural communities has effectively prevented the rural outflow. Pushpa B [15] 
believed that information and communication technologies (ICT) have enabled people to migrate from cities to rural areas, bringing employment opportunities to many people. Sapna A, Narula and Sabhyata Arora [16] found that farmers use village-level Internet sites for online ticket booking, online bill payment, and property information registration, bringing convenience to farmers' lives.Adamides et al. [17] believed that ICT can encourage communication among farmers and increase their participation and exchanges of skills and knowledge.

In terms of cultural value contribution, Krishan K. Boora [18] believed that rural e-commerce effectively promotes rural cultural activities.Zoltán Zakota [19] argued that e-commerce developing in areas such as agriculture or rural tourism will help strengthen the rural business atmosphere. Colom Gorgues and Antonio [20] held that the use of information and communication technologies (ICT) can help strengthen cultural, artistic, architectural and historical heritage to achieve a new geographical balance in the development of rural areas.

In terms of ecological value contribution, Jalali A A, Okhovvat M R, Okhovvat M [21] recognized that implementing e-commerce practices in rural areas is also an applicable and durable solution to the rural environment. Vajda-Mlinacek, Ljiljana, GradiBnik, et al. [22] studied e-commerce based on the promotion and sales of eco-tourism services. The results confirmed that the Internet is a good way to promote ecological destinations.

\section{Construction of Value Contribution Model of Rural E-commerce}

This research defines the value contribution of rural e-commerce based on previous researches and four sub-dimensions, namely economy, society, culture and ecology constructed on value dimension of the value contribution of the development of rural e-commerce as in the process of participating in e-commerce, farmers boost the economic, social, cultural and ecological performances in rural areas altogether with multiple visible results. The value contribution model proposed in this research recognizes the value of rural e-commerce from three levels, namely the overall level, the dimension level and the measurement items. The dimension layer mainly reflects the value of 4 aspects, namely economy, society, culture and ecology. On top of these four dimensional factors, there is an overall factor, namely the value of rural e-commerce. The value contribution model of rural e-commerce is shown in Table 1.

Table 1. Value contribution model of rural e-commerce

\begin{tabular}{|c|c|c|}
\hline Overarching dimension & Measuring dimension & Variable \\
\hline \multirow{4}{*}{$\begin{array}{c}\text { Rural E-commerce } \\
\text { (REC) }\end{array}$} & & Production mode EV2 \\
\cline { 2 - 3 } & & Product sales EV3 \\
\cline { 2 - 3 } & & Product brand EV4 \\
\cline { 2 - 3 } & & Economic value (EV) \\
\cline { 2 - 3 } & & Industrial service EV6 \\
\cline { 2 - 3 } & & Organization scale EV7 \\
\cline { 2 - 3 } & & Cost of sales EV8 \\
\cline { 2 - 3 } & & Infrastructure SV1 \\
\cline { 2 - 3 } & & Way of life SV2 \\
\cline { 2 - 3 } & & Social status SV3 \\
\hline
\end{tabular}


Volume 2021, No. 2

\begin{tabular}{|l|c|c|}
\hline Overarching dimension & Measuring dimension & Variable \\
\hline \multirow{4}{*}{} & Social value $(\mathrm{SV})$ & Returnee SV4 \\
\cline { 2 - 3 } & & Non-native personnel SV5 \\
\cline { 2 - 3 } & & Consumption capacity SV6 \\
\cline { 2 - 3 } & & Comprehensive quality SV7 \\
\cline { 2 - 3 } & & Ray of communication SV8 \\
\cline { 2 - 3 } & Cultural value $(\mathrm{CV})$ & Business atmosphere CV2 \\
\cline { 2 - 3 } & & Cultural fusion CV3 \\
\cline { 2 - 3 } & & Environmental awareness EcV1 \\
\cline { 2 - 3 } & Ecological value $(\mathrm{EcV})$ & Ecological product EcV2 \\
\cline { 2 - 3 } & & Ecological industry EcV3 \\
\hline
\end{tabular}

The value model contains a total of 22 measuring variables, of which the economic value dimension contains 8 variables, the social value dimension 8 variables, cultural value and ecological value both 3 variables, respectively, the name of the variable and its meaning is explained in Table 2.

\section{Research Methods}

\subsection{Questionnaire}

In order to obtain the first-hand data, the micro-data involved in this research was mainly collected by designing questionnaires for farmers and other relevant subjects, and conducting field surveys, Questionnaire for Farmers' Participation in Rural E-commerce in Zhejiang Province. The questionnaire survey used a combination of stratified sampling of cities and counties and random sampling of farmers, so the sample as a whole can represent the overall situation of Zhejiang Province. The survey of farmer households adopts the method of questionnaire, which is conducted by random households sampling. For farmer household survey, the questionnaire survey was completed by either surveyed farmer themselves or the inquiry of surveyors.

In this research, AMOS software was used, and a first-order structural equation model and a higher-order structural equation model were adopted to analyse the confirmatory factors of the value contribution model of rural e-commerce, and to test the convergence and discriminative validity of the model and other important attributes.

\section{Variable measurement and data collection}

\subsection{Variable measurement}

The development of the scale in this research has gone through multiple stages. In the first stage, a large number of domestic and foreign rural e-commerce documents have been reviewed. To ensure the validity of the scale, comparatively developed measurement items from previous researches were adopted. Finally, 29 measurement items were formed. In the second stage, 2 rural e-commerce professors, 2 e-commerce professors, 3 IT professors, and 6 doctoral students of relative majors were invited to group discussions, revising and selecting the 29 measurement items that have been formed, and finally it was decided that 29 items were streamlined to 26 items. In the third stage, in July 2019, 50 rural e-commerce practitioners were pre-tested. Through on-site interviews and exchanges with the officials of relevant rural e-commerce departments, the questionnaire measurement items were 
further improved and revised based on the actual operations of rural e-commerce. Finally, after the removal of 4 items and further improvement of item expressions, a questionnaire with 22 items was formed.

Table 2. Variables of value contribution model of rural e-commerce and descriptions

\begin{tabular}{|c|c|c|}
\hline $\begin{array}{l}\text { Measuring } \\
\text { dimension }\end{array}$ & variable & Variables description \\
\hline $\begin{array}{l}\text { Economic } \\
\text { value }\end{array}$ & EV1 & Compared with before, household income has been increased \\
\hline \multirow[t]{7}{*}{$(\mathrm{EV})$} & EV2 & Compared with before, production mode has changed \\
\hline & EV3 & Compared with before, product sales have been increased \\
\hline & EV4 & Compared with before, the popularity of products has increased \\
\hline & EV5 & $\begin{array}{c}\text { Compared with before, the efficiency of arranging production based on market } \\
\text { information feedback has been strengthened }\end{array}$ \\
\hline & EV6 & $\begin{array}{c}\text { Compared with before, industrial technical services and training have been } \\
\text { increased }\end{array}$ \\
\hline & EV7 & $\begin{array}{c}\text { Compared with before, the rural cooperative economic organization has a larger } \\
\text { scale }\end{array}$ \\
\hline & EV8 & Compared with before, the cost of sales has been reduced \\
\hline \multirow[t]{8}{*}{$\begin{array}{l}\text { Social value } \\
\quad(\mathrm{SV})\end{array}$} & SV1 & $\begin{array}{c}\text { Compared with before, rural infrastructure (roads, networks, etc.) has been further } \\
\text { improved }\end{array}$ \\
\hline & SV2 & Compared with before, lifestyle has changed (in terms of convenience) \\
\hline & SV3 & Compared with before, family's social status has been improved \\
\hline & SV4 & $\begin{array}{l}\text { Compared with before, there are more people returning to the village (migrant } \\
\text { workers, college students, etc.) }\end{array}$ \\
\hline & SV5 & Compared with before, there are more people coming from outside the village \\
\hline & SV6 & Compared with before, your family's consumption power has increased \\
\hline & SV7 & $\begin{array}{l}\text { Compared with before, your comprehensive qualities (literacy, communication } \\
\text { skills, e-commerce knowledge and skills, etc.) have been significantly improved }\end{array}$ \\
\hline & SV8 & Compared with before, way of communication has been more convenient \\
\hline \multirow{3}{*}{$\begin{array}{l}\text { Cultural } \\
\text { value } \\
(\mathrm{CV})\end{array}$} & CV1 & $\begin{array}{l}\text { Compared with the past, rural customs and civility (family harmony, cultural } \\
\text { diversity, etc.) have improved }\end{array}$ \\
\hline & CV2 & $\begin{array}{l}\text { Compared with before, the business atmosphere (more product display, sales } \\
\text { related topics discussion, fair competition and increased awareness of win-win } \\
\text { cooperation, etc.) has improved }\end{array}$ \\
\hline & CV3 & Compared with before, urban culture has been more integrated with other cultures \\
\hline \multirow{3}{*}{$\begin{array}{l}\text { Ecological } \\
\text { value } \\
(\mathrm{EcV})\end{array}$} & EcV1 & $\begin{array}{c}\text { Compared with before, environmental protection awareness has increased (no } \\
\text { littering, environmental protection, etc.) }\end{array}$ \\
\hline & $\mathrm{EcV} 2$ & $\begin{array}{l}\text { Compared with before, the sales of ecological products (decreased use of fertilizers, } \\
\text { pesticides, chemical agents, etc.) }\end{array}$ \\
\hline & $\mathrm{EcV} 3$ & $\begin{array}{c}\text { Compared with before, the industries have been more environmentally friendly, } \\
\text { light industries have been further developed, and sewage, exhaust gas, and waste } \\
\text { emission has been reduced }\end{array}$ \\
\hline
\end{tabular}

It is used to measure the value contribution of rural e-commerce, and the questionnaire is designed based on the four measuring dimensions formed by the theoretical model. The measurement items are measured by Likert five-level scale, 1 means "strongly agree", 2 "relatively agree", 3 "agree", 4 "disagree", and 5 "strongly disagree".

\subsection{Data collection and sample characterization}


According to the level of economic development, per capita GDP and per capita income in 2018, 11 prefecture-level cities in Zhejiang Province are divided into three tiers: economically developed, economically moderate and economically underdeveloped. One prefecture-level city is selected from each tier, and three counties are selected from each prefecture-level city by the same method. Each prefecture-level city was issued with 405 questionnaires and each county i135 questionnaires. A total of 1215 questionnaires were issued and 1183 were recovered, thus the recovery rate is $97.36 \%$, among all the questionnaires, 1111 are valid with an effective rate of $91.44 \%$. At the same time, the questionnaire survey for farmers was conducted from July to October in 2019, and the survey time was relatively concentrated, so there was no response deviation in time. Table 3 provides a descriptive statistics of the collected data.

Table 3. Descriptive statistics of the collected data

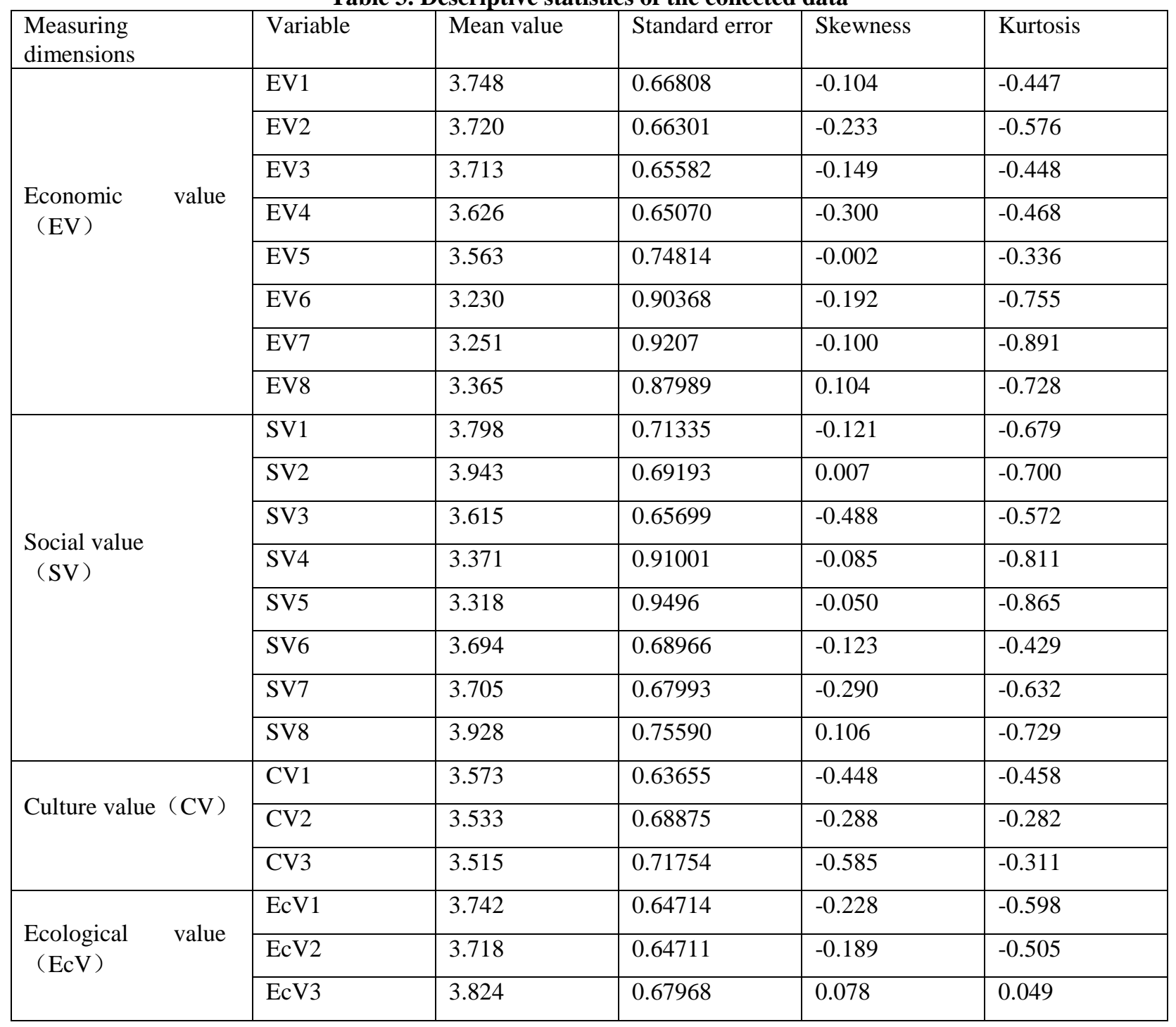

In this research, the statistics of the items contained in the four dimensions show that the absolute value of Skewness of EV containing 8 items ranges between 0.002-0.300, the absolute value of Kurtosis between 0.336-0.755. In SV, the former containing 8 items is between 0.007-0.488, the latter between 0.429- 0.811. The two values in CV covering 3 items are between $0.288-0.585$ and $0.282-0.458$ respectively, 3 items in EcV between 0.078-0.228 and 0.049-0.598 respectively. The absolute values of Skewness and Kurtosis of the items contained in each dimension are all smaller than 3 , indicating that the data meets the requirements of the normal distribution statistically. 


\section{Recognition model structure validity and reliability}

The author consulted a large number of rural e-commerce and related literature, thus ensured that the questionnaire items could well reflect the four value contribution dimensions of rural e-commerce value. Two professors of rural commerce, two e-commerce professors, three IT professors and six doctoral students in related majors conducted group discussions to determine the measurement variables. Through pre-test and interviews with the surveyed farmers, the content validity of the questionnaire was ensured by logical analysis. SPSS24.0 was used to analyse the exploratory factor and reliability of the data.

\subsection{Exploratory Factor Analysis}

The objective of conducting exploratory factor analysis is to set up the structural validity of the scale or the questionnaire established [23]. The KMO value of the survey data and Bartlett's test is adopted to judge if the questionnaire is suitable for factor analysis. The KMO value is between 0 and 1 . The prerequisite of conducting factor analysis on the scale is the KMO value of the scale data above 0.70 and the $\mathrm{P}$ value less than 0.05 . Exploratory factor analysis adopts principal component analysis, extracting factors with eigenvalues larger than the value of 1 , and orthogonal rotation is achieved with maximum variance method. Among common factors, the contribution rate of cumulative variance is expected to be higher than $60 \%$, and each factor generally contains at least three items. Items with factor loading less than 0.50 and commonality less than 0.40 are deleted. In addition, items with factor loading greater than 0.45 in both common factors should also be deleted. According to the standards above, the value recognition model of rural e-commerce is analysed by EFA, and the results are shown in Table 4, Table 5 and Table 6.

Table 4. KMO and Bartlett's test

\begin{tabular}{|l|l|l|}
\hline \multicolumn{2}{|l|}{ KMO sampling suitability } & \multicolumn{1}{c|}{0.947} \\
\hline \multirow{2}{*}{ Bartlett's test } & Approximate Chi-square & 13831.806 \\
\cline { 2 - 3 } & Degree of freedom & 190 \\
\cline { 2 - 3 } & Significance & 0.000 \\
\hline
\end{tabular}

From the table 4, it can be noted that the KMO value of the questionnaire items is 0.947 , and the approximate Chi-square value is $13831.806, \mathrm{P}<0.001$, which meet the standards and requirements of factor analysis in statistics.

Table 5. Total statistics

\begin{tabular}{|c|c|c|c|c|}
\hline $\begin{array}{c}\text { Measurement } \\
\text { items }\end{array}$ & Mean value & variance & correlation & Alpha \\
\hline EV1 & 50.2547 & 97.309 & 0.703 & 0.924 \\
\hline EV2 & 50.2268 & 98.703 & 0.598 & 0.926 \\
\hline EV3 & 50.2196 & 98.532 & 0.619 & 0.926 \\
\hline EV4 & 50.1332 & 98.916 & 0.593 & 0.926 \\
\hline EV5 & 50.0702 & 97.370 & 0.616 & 0.926 \\
\hline EV6 & 49.7363 & 94.692 & 0.655 & 0.925 \\
\hline EV7 & 49.7579 & 98.870 & 0.399 & 0.931 \\
\hline EV8 & 49.8713 & 94.779 & 0.669 & 0.925 \\
\hline SV1 & 50.3051 & 97.708 & 0.624 & 0.926 \\
\hline SV2 & 50.4500 & 98.013 & 0.622 & 0.926 \\
\hline SV3 & 50.1215 & 98.401 & 0.628 & 0.926 \\
\hline
\end{tabular}




\begin{tabular}{|c|c|c|c|c|}
\hline $\begin{array}{c}\text { Measurement } \\
\text { items }\end{array}$ & Mean value & variance & correlation & Alpha \\
\hline SV4 & 49.8776 & 93.410 & 0.727 & 0.923 \\
\hline SV5 & 49.8245 & 100.720 & 0.283 & 0.933 \\
\hline SV6 & 50.2007 & 97.966 & 0.628 & 0.926 \\
\hline SV7 & 50.2115 & 98.219 & 0.619 & 0.926 \\
\hline SV8 & 50.4347 & 96.464 & 0.672 & 0.925 \\
\hline CV1 & 50.0801 & 99.357 & 0.572 & 0.927 \\
\hline CV2 & 50.0396 & 98.233 & 0.609 & 0.926 \\
\hline CV3 & 50.0216 & 98.727 & 0.545 & 0.927 \\
\hline EcV1 & 50.2484 & 99.208 & 0.573 & 0.926 \\
\hline EcV2 & 50.2250 & 99.203 & 0.574 & 0.926 \\
\hline EcV3 & 50.3312 & 97.681 & 0.661 & 0.925 \\
\hline
\end{tabular}

At last, after three orthogonal rotations, a stable and clear dimensional structure was obtained, and two questions, EV7(0.399) and SV5(0.283), with commonality less than 0.50 and factor load less than 0.6, were deleted, as shown in table 5. The results are shown in Table 6 below.

Table 6. Exploratory factor analysis results

\begin{tabular}{|c|c|c|c|c|c|c|c|c|}
\hline & \multicolumn{3}{|c|}{ component } & commonalit & Eigenvalue & Variance \% & $\begin{array}{c}\text { cumulative } \\
\text { variance } \\
\text { Contribution } \\
\text { rate\% }\end{array}$ \\
\cline { 2 - 8 } & 1 & 2 & 3 & 4 & & & & \\
\hline SV4 & 0.840 & & & & 0.815 & & & \\
\hline SV8 & 0.824 & & & & 0.760 & & & \\
\hline SV1 & 0.773 & & & & 0.661 & 4.782 & 23.912 & 23.912 \\
\hline SV7 & 0.766 & & & & 0.654 & & & \\
\hline SV6 & 0.759 & & & & 0.648 & & & \\
\hline SV3 & 0.730 & & & & 0.618 & & & \\
\hline SV2 & 0.674 & & & & 0.568 & & & \\
\hline EV8 & & 0.823 & & & 0.751 & & & \\
\hline EV2 & & 0.776 & & & 0.651 & & & \\
\hline EV4 & & 0.775 & & & 0.646 & & & \\
\hline EV5 & & 0.755 & & & 0.643 & 4.634 & 23.169 & 47.080 \\
\hline EV1 & & 0.746 & & & 0.690 & & & \\
\hline EV6 & & 0.733 & & & 0.640 & & & \\
\hline EV3 & & 0.712 & & & 0.595 & & & \\
\hline CV3 & & & 0.795 & & 0.740 & & & \\
\hline CV2 & & & 0.774 & & 0.754 & 2.269 & 11.345 & 58.426 \\
\hline CV1 & & & 0.773 & & 0.736 & & & \\
\hline EcV2 & & & & 0.782 & 0.754 & & & \\
\hline EcV1 & & & & 0.777 & 0.742 & 2.210 & 11.049 & 69.475 \\
\hline EcV3 & & & & 0.769 & 0.817 & & & \\
\hline
\end{tabular}

From table 6, there are 4 common factors with eigenvalues greater than 1, which are 4.782, 4.634, 2.269 and 2.210 respectively, and the cumulative variance contribution rate of $\mathrm{SV}, \mathrm{EV}, \mathrm{CV}$ and $\mathrm{EcV} 4$ is 69.475 , which meets the 
statistical standard. It proves that the four common factors extracted in this research effectively interpret the 20 items of the questionnaire and realise the goal of dimension reduction. And the corresponding factor loading in the items included in each factor after rotation is greater than 0.60 , indicating that these items can well fall into the corresponding contribution dimensions. In addition, the extraction rate of common factors for each topic is greater than 0.50 , which indicates that the interpretation degree of extracted factors for each topic can reach more than $50 \%$, so the extracted factors are suitable.

It can also be seen from the scree plot that the flattening of the chart starts from the fifth factor, so it is more appropriate to retain four factors, which also proves that the number of factors extracted by factor rotation is reasonable. As it is shown in figure1.

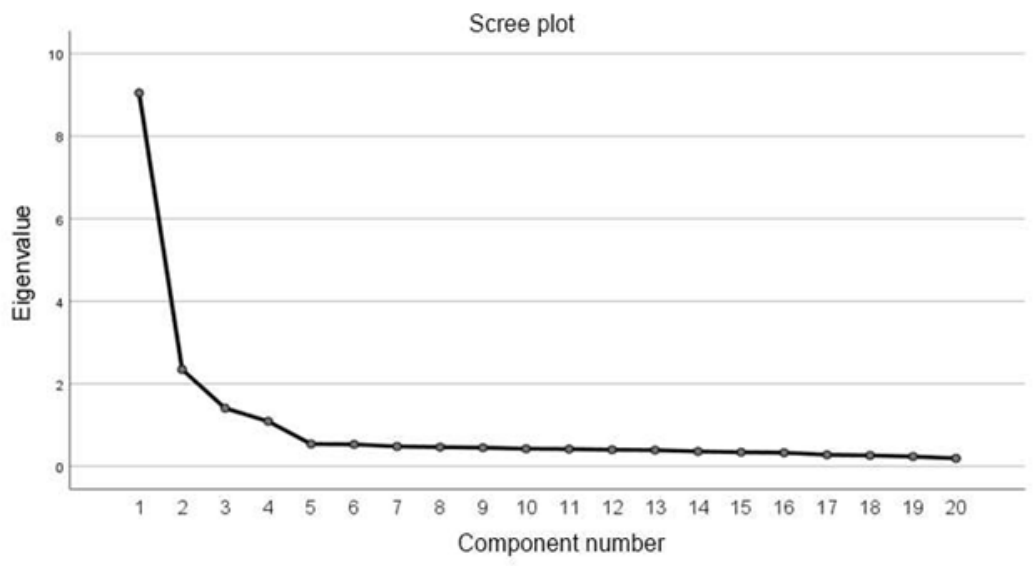

Fig.1. scree plot

6.2. Reliability test

Table 7. Reliability analysis

\begin{tabular}{|c|c|c|}
\hline Dimension & Cronbach's Alpha & Number of items \\
\hline EV & 0.909 & 7 \\
\hline SV & 0.918 & 3 \\
\hline CV & 0.830 & 3 \\
\hline EcV & 0.844 & 20 \\
\hline NXEV & 0.935 & 7 \\
\hline
\end{tabular}

From the reliability analysis results in table 7, the Cronbach's Alpha coefficient of the 20 items in the questionnaire is 0.935 , and the four reliability coefficients of EV, SV, CV, and EcV are between 0.830-0.918. The reliability of the total questionnaire and the four dimensions of $\mathrm{EV}, \mathrm{SV}, \mathrm{CV}$ and $\mathrm{EcV}$ meet the statistical requirements. See Table 7 .

\subsection{Confirmatory analysis}

Factor analysis is a common method to investigate the structural validity. In light of the results obtained from the exploratory factor analysis, this research preliminarily determined the questionnaire structure, and confirmatory factor analysis was adopted to evaluate the established questionnaire structure through data fitting indicators. The factor loading value in the model obtained by confirmatory factor analysis was used to calculate convergence and discrimination validity.

\subsubsection{Analysis of confirmatory factors at dimension level}


Confirmatory factor analysis has been carried out with the data from formal test, and the results are following:

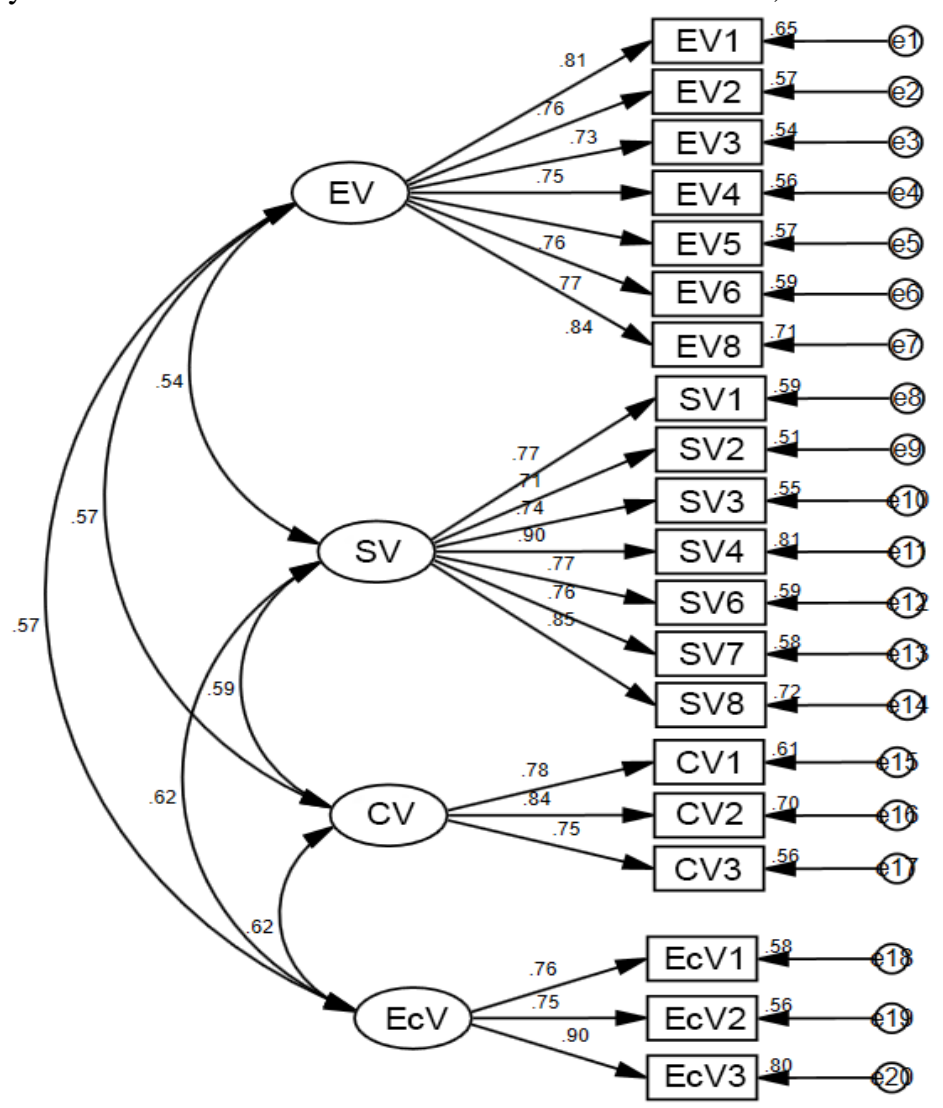

Fig.2. Confirmatory factor analysis structure

The fitting indexes at dimension level of confirmatory factor analysis are exhibited in Table 8 .

Table 8. Fitting indexes of confirmatory factor analysis at dimension level

\begin{tabular}{|c|c|c|c|c|}
\hline Indicator & Test statistic & $\begin{array}{l}\text { Adaptation standard or } \\
\text { critical value }\end{array}$ & Test result & Model adaptation \\
\hline \multirow{7}{*}{$\begin{array}{l}\text { Absolute fit } \\
\text { index }\end{array}$} & $\chi^{2}$ & & 451.975 & \\
\hline & $\mathrm{df}$ & & 164 & \\
\hline & $\mathrm{P}$ & $\geq 0.05$ & 0.000 & NO \\
\hline & SRMR & $\leq 0.05$ & 0.014 & YES \\
\hline & RMSEA & $\leq 0.08$ & 0.040 & YES \\
\hline & GFI & $\geq 0.90$ & 0.961 & YES \\
\hline & AGFI & $\geq 0.90$ & 0.950 & YES \\
\hline \multirow{5}{*}{$\begin{array}{l}\text { Value-added fit } \\
\text { index }\end{array}$} & NFI & $\geq 0.90$ & 0.968 & YES \\
\hline & RFI & $\geq 0.90$ & 0.962 & YES \\
\hline & IFI & $\geq 0.90$ & 0.979 & YES \\
\hline & TLI & $\geq 0.90$ & 0.976 & YES \\
\hline & CFI & $\geq 0.90$ & 0.979 & YES \\
\hline \multirow{4}{*}{$\begin{array}{l}\text { Reduced fit } \\
\text { index }\end{array}$} & PGFI & $\geq 0.50$ & 0.750 & YES \\
\hline & PNFI & $\geq 0.50$ & 0.835 & YES \\
\hline & PCFI & $\geq 0.50$ & 0.845 & YES \\
\hline & $\chi^{2} / \mathrm{df}$ & $\leq 2.00$ & 2.756 & YES \\
\hline
\end{tabular}

ISSN: 0010-8189 
The fit index value of the model is obtained by confirmatory factor analysis. As the table above shows, from the overall situation of the fit index value, other fit index values have reached the evaluation standard of model fitting in statistics except $\mathrm{P}$ value, which shows that the structure of rural e-commerce value model has been verified and the questionnaire structure is accurate and effective.

6.3.2. Overall confirmatory factor analysis

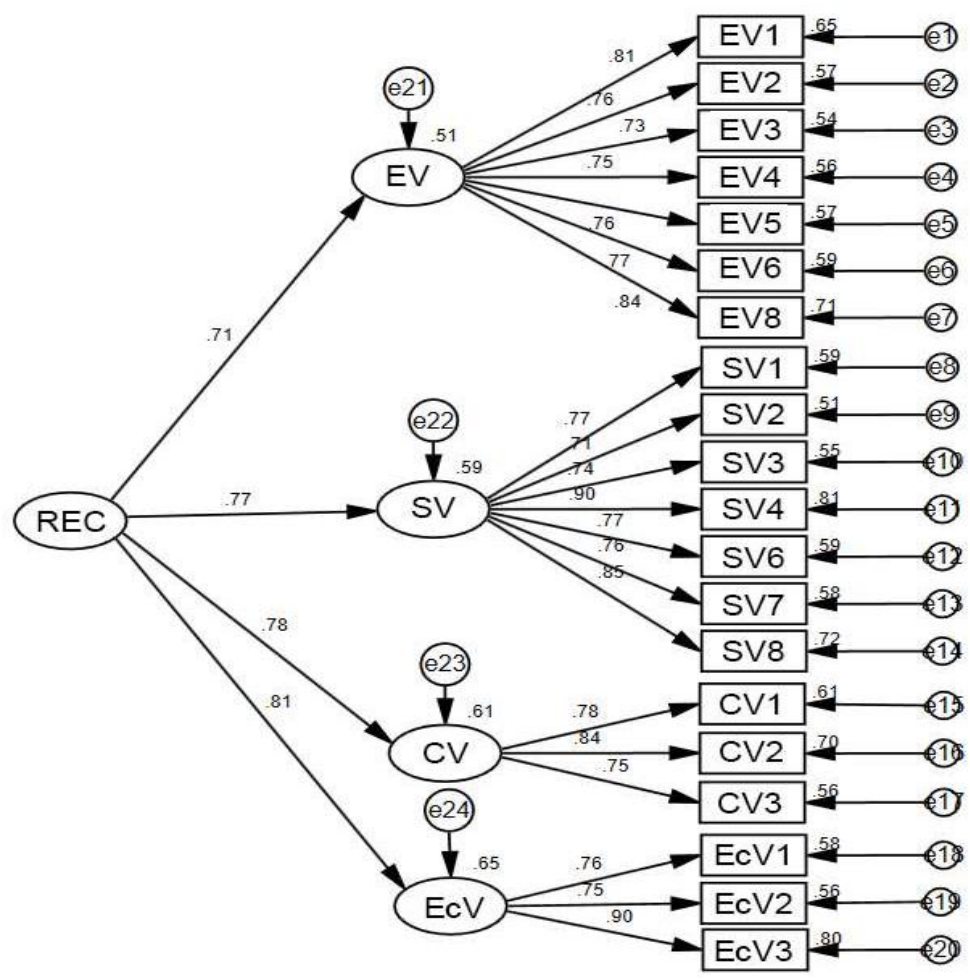

Fig.3. Overall confirmatory factor analysis of rural e-commerce value

After calculation, the overall layer factor model fit index is shown in Table 9. The fit index shows that the model matches well with the sample data.

Table 9. Overall confirmatory factor analysis fit indicators

\begin{tabular}{|c|c|c|c|c|c|c|}
\hline Indicator & $X^{2}$ & $\mathrm{df}$ & $\mathrm{X}^{2} / \mathrm{df}$ & SRMR & GFI & AGFI \\
\hline $\begin{array}{c}\text { Acceptance } \\
\text { standard }\end{array}$ & & & $1-3$ & $<0.05$ & $>0.9$ & $>0.9$ \\
\hline $\begin{array}{l}\text { Overall } \\
\text { factor } \\
\text { model }\end{array}$ & 452.522 & 166 & 2.726 & 0.029 & 0.961 & 0.950 \\
\hline Match & & & YES & YES & YES & YES \\
\hline Indicator & NFI & IFI & TLI & CFI & RMSEA & \\
\hline $\begin{array}{c}\text { Acceptance } \\
\text { standard }\end{array}$ & $>0.9$ & $>0.9$ & $>0.9$ & $>0.9$ & $<0.08$ & \\
\hline $\begin{array}{l}\text { Overall } \\
\text { factor }\end{array}$ & 0.968 & 0.979 & 0.976 & 0.979 & 0.039 & \\
\hline
\end{tabular}

ISSN: 0010-8189 


\begin{tabular}{|c|c|c|c|c|c|c|}
\hline model & & & & & & \\
\hline Match & YES & YES & YES & YES & YES & \\
\hline
\end{tabular}

With confirmatory factor analysis, the fit indicators of the overall measurement model are obtained. From the statistical results, it can be concluded that all fitting indicators reach the ideal value. The structure of the model is verified, and the questionnaire structure is accurate and effective.

\subsection{Validity test}

Through confirmatory factor analysis of the factor loading of each item in the corresponding dimension, the convergence validity and discrimination validity can be further calculated. The results are as follows.

Table 10. Convergence validity

\begin{tabular}{|c|c|c|c|c|}
\hline & EcV & CV & SV & EV \\
\hline EcV & 0.774 & & & \\
\hline CV & 0.625 & 0.789 & & 0.790 \\
\hline SV & 0.622 & 0.595 & 0.543 & 0.806 \\
\hline EV & 0.573 & 0.566 & & \\
\hline
\end{tabular}

In Table 10, the first value in each column is the square root of the four dimensions AVE of EcV, CV, SV, EV, which are $0.774,0.789,0.790,0.806$ respectively. The absolute values of the correlation coefficients between EcV and CV, SV, EV are respectively $0.625,0.622,0.573$, the absolute value of the correlation coefficient between CV and $\mathrm{SV}, \mathrm{EV}$ is $0.595,0.566$, and the absolute value of the correlation coefficient between $\mathrm{SV}$ and $\mathrm{EV}$ is 0.543 . It can be concluded that the square roots of the AVE values of the four dimensions of EcV, CV, SV, and EV are all greater than the correlation coefficients of this dimension compared with other dimensions, indicating that the discrimination validity of these four dimensions has reached the statistical standard.

Table 11 Parameter table of confirmatory factor analysis model at dimension level

\begin{tabular}{|c|c|c|c|c|c|c|c|c|c|}
\hline & & & Estimate & S.E. & C.R. & $\mathrm{P}$ & $\begin{array}{l}\text { Factor } \\
\text { loading }\end{array}$ & $\mathrm{CR}$ & AVE \\
\hline $\mathrm{EV}$ & $<--$ & REC & 1.000 & & & & 0.715 & \multirow{4}{*}{0.851} & \multirow{4}{*}{0.589} \\
\hline SV & $<--$ & REC & 1.087 & 0.066 & 16.559 & $* * *$ & 0.766 & & \\
\hline $\mathrm{CV}$ & $<--$ & REC & 1.003 & 0.061 & 16.438 & $* * *$ & 0.780 & & \\
\hline $\mathrm{EcV}$ & $<--$ & REC & 1.028 & 0.062 & 16.601 & $* * *$ & 0.806 & & \\
\hline EV1 & $<--$ & $\mathrm{EV}$ & 1.000 & & & & 0.808 & \multirow{7}{*}{0.913} & \multirow{7}{*}{0.599} \\
\hline EV2 & $<--$ & $\mathrm{EV}$ & 0.929 & 0.034 & 27.607 & $* * *$ & 0.757 & & \\
\hline EV3 & $<--$ & EV & 0.891 & 0.033 & 26.885 & $* * *$ & 0.733 & & \\
\hline EV4 & $<---$ & $\mathrm{EV}$ & 0.906 & 0.033 & 27.422 & $* * *$ & 0.751 & & \\
\hline EV5 & $<--$ & $\mathrm{EV}$ & 1.048 & 0.038 & 27.850 & $* * *$ & 0.756 & & \\
\hline EV6 & $<--$ & $\mathrm{EV}$ & 1.283 & 0.045 & 28.417 & $* * *$ & 0.767 & & \\
\hline EV8 & $<---$ & $\mathrm{EV}$ & 1.373 & 0.043 & 31.928 & $* * *$ & 0.842 & & \\
\hline SV1 & $<---$ & SV & 1.000 & & & & 0.768 & \multirow{2}{*}{0.920} & \multirow{2}{*}{0.622} \\
\hline SV2 & $<--$ & SV & 0.900 & 0.036 & 24.731 & $* * *$ & 0.712 & & \\
\hline
\end{tabular}




\begin{tabular}{|c|c|c|c|c|c|c|c|c|c|}
\hline & & & Estimate & S.E. & C.R. & $\mathrm{P}$ & $\begin{array}{c}\text { Factor } \\
\text { loading }\end{array}$ & CR & AVE \\
\hline $\mathrm{EV}$ & $<--$ & REC & 1.000 & & & & 0.715 & \multirow{9}{*}{0.851} & \multirow{9}{*}{0.589} \\
\hline SV & $<--$ & REC & 1.087 & 0.066 & 16.559 & $* * *$ & 0.766 & & \\
\hline $\mathrm{CV}$ & $<---$ & REC & 1.003 & 0.061 & 16.438 & $* * *$ & 0.780 & & \\
\hline $\mathrm{EcV}$ & $<--$ & REC & 1.028 & 0.062 & 16.601 & $* * *$ & 0.806 & & \\
\hline SV3 & $<---$ & SV & 0.891 & 0.034 & 25.989 & $* * *$ & 0.743 & & \\
\hline SV4 & $<--$ & SV & 1.496 & 0.045 & 32.897 & $* * *$ & 0.901 & & \\
\hline SV6 & $<--$ & SV & 0.966 & 0.036 & 27.009 & $* * *$ & 0.768 & & \\
\hline SV7 & $<---$ & SV & 0.948 & 0.035 & 27.037 & $* * *$ & 0.764 & & \\
\hline SV8 & $<--$ & SV & 1.169 & 0.038 & 30.426 & $* * *$ & 0.847 & & \\
\hline CV1 & $<--$ & $\mathrm{CV}$ & 1.000 & & & & 0.780 & \multirow{3}{*}{0.832} & \multirow{3}{*}{0.624} \\
\hline CV2 & $<--$ & $\mathrm{CV}$ & 1.160 & 0.044 & 26.471 & $* * *$ & 0.836 & & \\
\hline CV3 & $<--$ & $\mathrm{CV}$ & 1.086 & 0.045 & 24.388 & $* * *$ & 0.751 & & \\
\hline EcV1 & $<---$ & $\mathrm{EcV}$ & 1.000 & & & & 0.760 & \multirow{3}{*}{0.846} & \multirow{3}{*}{0.649} \\
\hline $\mathrm{EcV} 2$ & $<--$ & $\mathrm{EcV}$ & 0.988 & 0.040 & 24.813 & $* * *$ & 0.751 & & \\
\hline EcV3 & $<--$ & $\mathrm{EcV}$ & 1.239 & 0.044 & 28.304 & $* * *$ & 0.897 & & \\
\hline
\end{tabular}

From table 11, the CR values of EcV, CV, SV and EV are 0.913, 0.920, 0.832 and 0.846, which are all greater than 0.70 , and the AVE values of EcV, CV, SV and EV are 0.599, 0.622, 0.624 and 0.649 respectively, all greater than 0.50 , showing that the combined reliability and convergence validity of the four dimensions have reached the statistical standard.

As far as REC is concerned, the normalized factor loading of EcV, CV, SV and EV in REC are 0.806, 0.780, 0.766 and 0.715 , respectively. Based on this, the CR value and AVE value of REC are 0.851 and 0.589 , indicating that the combination reliability and convergence validity of REC also meet the statistical requirements.

\section{Principal components of overall dimension and index weight}

The results of confirmatory factor analysis at dimension level show that the coefficients between EV dimension and SV, CV and EcV are 0.54, 0.57 and 0.57 respectively, all less than 0.6; Coefficient between SV and CV is 0.59 , less than 0.6; Coefficient between $\mathrm{SV}$ and $\mathrm{EcV}$ and between $\mathrm{CV}$ and $\mathrm{EcV}$ are all 0.62, which is similar to 0.6. Therefore, EV, SV, CV and EcV are related to but do not contain each other, and the four dimensions have good discrimination reliability.

According to the factor loading and each principal component's contribution rate, the weight of the overall dimension principal component and its index is obtained, as shown in Table 12. According to Table 12, the weights of EV, SV, CV and EcV are 0.344, 0.333, 0.163 and 0.159 , respectively, indicating that the development of rural e-commerce has valuable contributions to farmers' economy, society, culture and ecology. Among these four value contributions, the development of rural e-commerce has the greatest contribution to economic value, followed by social value and culture See table 12 for index weights of each dimension layer. 
Table 12. Principal components of overall dimensions and index weights

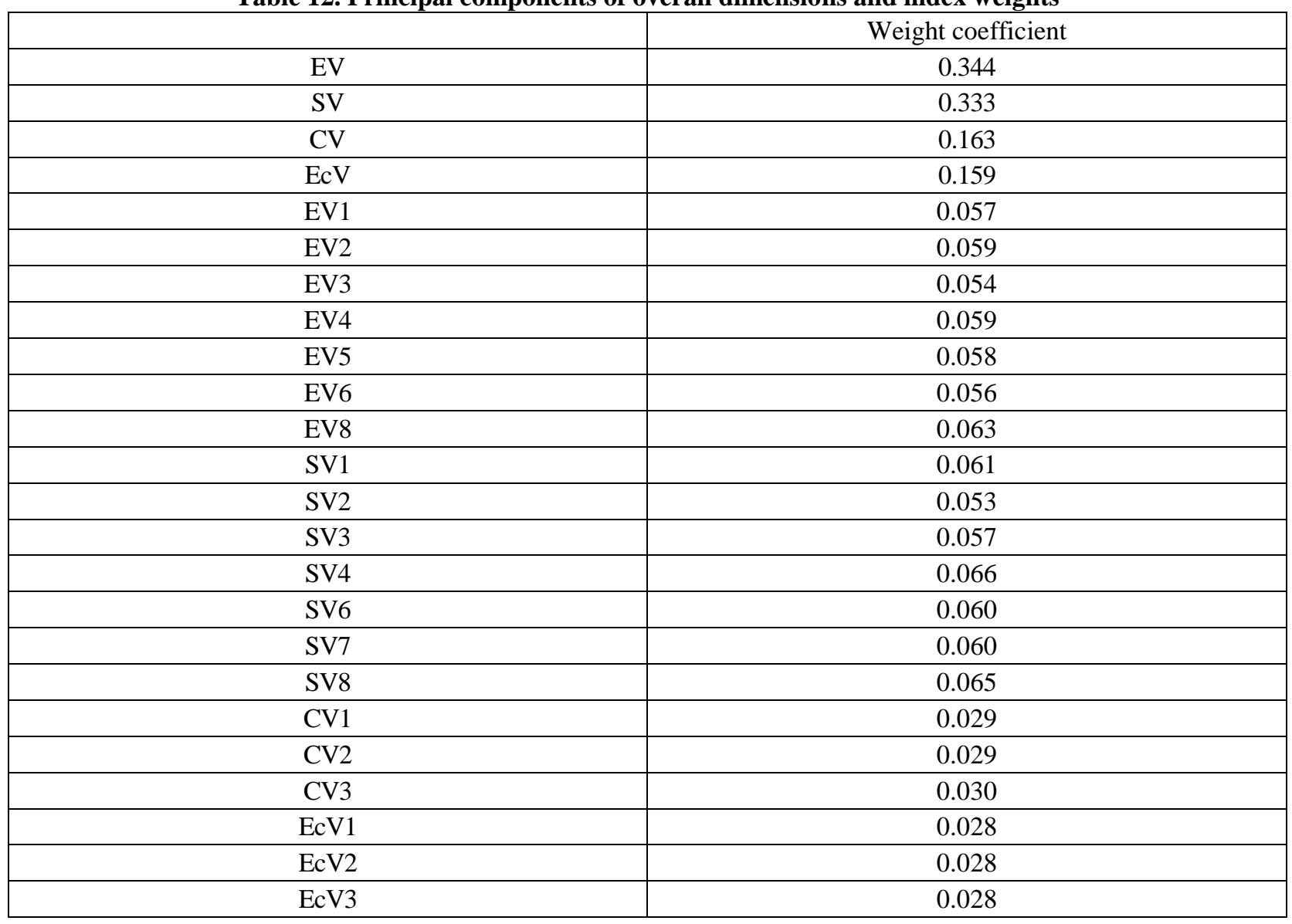

\section{Results and discussions}

The rural e-commerce value contribution model is a multi-dimensional structure. The value contribution model of rural e-commerce consists of four value dimensions: economy, society, culture and ecology, and the dimension of "economic value" includes seven indicators: household income, production mode, product sales, product brand, market sensitivity, industrial service and sales cost. The dimension of "social value" includes seven indicators: infrastructure, lifestyle, social status, returnees, spending power, comprehensive quality and communication methods. The dimension of "cultural value" includes three indicators: rural civilization, commercial atmosphere and cultural integration, while the dimension of "ecological value" includes three indicators: environmental awareness, ecological products and ecological industry, which is a multidimensional structural model.

Exploratory factor analysis shows that the Cronbach Alpha coefficient of 20 items in the total questionnaire is 0.935, and the reliability coefficients of EV, SV, CV and EcV are between 0.830 and 0.918 , which indicates that the reliability of the total questionnaire and $\mathrm{EV}, \mathrm{SV}, \mathrm{CV}$ and $\mathrm{EcV}$ all meet the statistical requirements.

The results of confirmatory factor analysis at dimension level show that the coefficients between EV dimension and SV, CV and EcV are 0.54, 0.57 and 0.57, respectively, which are all less than 0.6; Coefficient between SV and $\mathrm{CV}$ is 0.59, less than 0.6; Coefficient between SV and EcV and between CV and EcV are all 0.62, which is similar to 0.6. Therefore, $\mathrm{EV}, \mathrm{SV}, \mathrm{CV}$ and $\mathrm{EcV}$ are related to each other but do not contain each other, and the four dimensions have good discrimination reliability.

Principal component analysis shows that rural e-commerce development has valuable contributions to farmers' 
economy, society, culture and ecology. Among these four value contributions, rural e-commerce development has the greatest contribution to economic value, followed by social value and cultural value, while rural e-commerce development has the least contribution to ecological value.

\section{References}

[1] W. S.Cheah, A.B.Masli, E. Mit, Sustainability Modelling of e-Commerce for Rural Community: A Case from Long Lamai e-Commerce Initiative// International Conference on Informatics and Creative Multimedia. IEEE Computer Society.pp. 282-287, 2013.

[2] L. Galloway, R. Mochrie, The use of ICT in rural firms: a policy - orientated literature review. info, vol. 7,no.3, pp. 33-46, 2005.

[3] YixuanWang, Social embedding of technology: a study on the formation mechanism of agricultural product taobao village - Empirical Analysis Based on W Village. Journal of Southwest University(Social Sciences Edition), vol. 46,no.1, pp. 61-68, 2020.

[4] GengLin, XiaoruXie, ZuyiLv, Taobao practices, everyday life and emerging hybrid rurality in contemporary China. Journal of Rural Studies, vol. 47,no. B, pp. 514-523, 2016.

[5] Lili Liu, et al, Study on the Influence of Agricultural Eco-Environment on the Competitiveness of Agricultural Products E-Commerce Brands in Jilin Province. 2019 IOP Conf. Ser.: Earth Environ. Sci. pp. 1-7, 2019.

[6] YingnanZhang, HualouLong, Shuangshuang Tu, et al, A Multidimensional Analysis of Rural Restructuring Driven by E-commerce: A Case of Xiaying Village in Central China. Scientia Geographica Sinica, vol. 39, no.6, pp. 947-955, 2019.

[7] A. Khanal, A. Mishra, Financial performance of small farm business households: the role of internet. China Agricultural Economic Review, vol.8,no.4, pp. 553-571, 2016.

[8] Jain Simple, Anuprita Purohit, Utilization of Agriculture Service of E-Choupal by Rural People of Rajasthan. International Journal of Home Science Extension and Communication Management. vol. 2, Issue .1, pp. 45-48, 2015.

[9] Alan Lukose, Rural Farmers Awareness towards E-Marketing Facilities Special Reference to Farmers of Ottapalam Taluk. International Journal of Emerging Technologies in Engineering Research, vol. 6, Issue Special.1,pp. 18-20, 2018.

[10] Haibin Zhang, Guoqing Zhang, Emotion Model Construction and Tendency Analysis on Neural Network-based Agricultural Product Network Comments. Revista de la Facultad de Ingenieria, vol.32, no. 11, pp. 745-751, 2017.

[11] J. Rhodes, Can E- Commerce Enable Marketing in an African Rural Women's Community Based Development Organization? Informing Science the International Journal of an Emerging Transdiscipline, vol. 6, pp. 157, 2003.

[12] F, Fariba, M S. Ebrahimi, FACTORS AFFECTING THE SOCIAL DEVELOPMENT OF RURALWOMEN- A CASE STUDY FROM IRAN. Indian Journal of Fundamental and Applied Life Sciences, vol. 4, no. 3, pp. 637-640, 2014.

[13] K. Georgiadou, W. Baros, G. Kekkeris, Motivating Roma women through computer education in

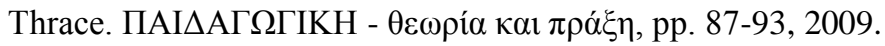

[14] Alibaygi. Amirhossein, Karamidehkordi. Mehdi, Mehrdad Pouya, Using the Delphi technique to assess cost-effectiveness of rural information and communications technologies (ICT) centers in Iran. Journal of Agricultural Extension and Rural Development, vol. 20,no.4, pp. 552-555, 2012.

[15] B. Pushpa, e-Farmers Friendly App for Rural Development. International Journal for Research in Engineering Application \& Management (IJREAM). pp. 27-30, 2018.

[16] Sapna A, Narula, Sabhyata Arora, Identifying stakeholders' needs and constraints in adoption of ICT services in rural areas: the case of India. SOCIAL RESPONSIBILITY JOURNAL, vol. 6. no.2, pp. 222-236, 2010. 
[17] G. Adamides, A. Stlianou, P. C .Kosmas, et al, Factors affecting PC and internet usage by the rural population of Cyprus. Agricultural Economics Reviews, vol. 14. no.1, pp. 16-36, 2013.

[18] K. BooraKrishan, Leveraging ICT in Rural \& Agriculture Market of India: An Overview. International Journal of Research in Management, Science \& Technology, vol. 8,no: 2, pp. 56-60, 2014.

[19] Z. Zakota, Bringing E-Business to Rural Regions Through Telecentre Networks. Journal of Applied Economic Sciences, vol. 1,no. 1. pp. 7, 2008.

[20] Colom Gorgues, Antonio, Innovacion organizacional y domesticacion de Internet y las TIC en el mundo rural, con nuevas utilidades colectivas y sociales. La figura del Telecentro y el Teletrabajo. (Organisational Innovation and Widespread Domestic Use of the Internet and ICTs in the Rural World, with New Collective and Social Utilities: Tele-centres and Tele-work. With English summary). CIRIEC-Espana, Revista de Economia Publica, Social y Cooperativa, vol. 49, pp.77-116, 2004.

[21] A A .Jalali, M .R.Okhovvat, M. Okhovvat, A new applicable model of Iran rural e-commerce development. Procedia Computer Science, vol. 3, pp. 1157-1163, 2011.

[22] Vajda-Mlinacek Ljiljana, GradiBnik Vera, E-trgovina u ekoturizmu. (E-Commerce in Ecotourism. With English summary). Character Educ, vol. 7,no. 1-2, pp. 151-158, 2001.

[23] Minglong Wu, Structural Equation Model - the practice and application of AMOS. pp. 212-213, 2010. 